\title{
AC impedance spectroscopy and conductivity studies of Dy doped $\mathrm{Bi}_{4} \mathbf{V}_{2} \mathrm{O}_{11}$ ceramics
}

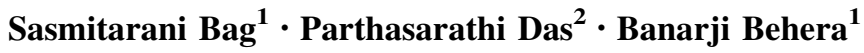

Received: 28 November 2016/Accepted: 11 March 2017/Published online: 22 March 2017

(c) The Author(s) 2017. This article is an open access publication

\begin{abstract}
The ac impedance and conductivity properties of Dy doped $\mathrm{Bi}_{4} \mathrm{~V}_{2}-{ }_{x} \mathrm{Dy}_{x} \mathrm{O}_{11}(x=0.05,0.10,0.15$ and 0.20$)$ ceramics prepared by solid-state reaction technique, in a wide frequency range at different temperatures have been studied. All the samples exhibited $\beta$-type phase orthorhombic structure at room temperature. The Nyquist plot confirmed the presence of both grain and grain boundary effects for all Dy doped samples. Double relaxation behavior was also observed. The grain and grain boundary resistance decreases with rise in temperature for all the concentration and exhibits a typical negative temperature co-efficient of resistance (NTCR) behavior. An analysis of the electric modulus suggests the possible hopping mechanism for electrical transport processes of all the materials. The ac conductivity spectrum obeys Jonscher's universal power law. DC conductivity of the materials were also studied and values of the activation energy found to be $0.40,0.49,0.73$ and $0.78 \mathrm{eV}$ for the compositions $x=0.05,0.10,0.15$ and 0.20 , respectively, at different temperatures $\left(150-375{ }^{\circ} \mathrm{C}\right)$.
\end{abstract}

Keywords Solid-state reaction - Aurivillius - X-ray diffraction - Grain boundary $\cdot$ Conductivity

Banarji Behera

banarjibehera@gmail.com

1 Material Research Laboratory, School of Physics, Sambalpur University, Jyoti Vihar, Burla, Odisha 768 019, India

2 Department of Physics, Midnapore College (Autonomous), Medinipur, West Bengal 721 101, India

\section{Introduction}

Layered bismuth oxides of the general formula $\left(\mathrm{Bi}_{2} \mathrm{O}_{2}\right)^{2+}$ $\left(\mathrm{A}_{m-1} \mathrm{~B}_{m} \mathrm{O}_{3 m+1}\right)^{2-}$ discovered by first Aurivillius [1]. Where A cations are generally $\mathrm{K}^{1+}, \mathrm{Ba}^{2+}, \mathrm{Sr}^{2+}, \mathrm{Ca}^{2+}$, $\mathrm{Bi}^{3+}$, etc. while the $\mathrm{B}$ cations are $\mathrm{Fe}^{3+}, \mathrm{Ti}^{4+}, \mathrm{Nb}^{5+}, \mathrm{W}^{6+}$ and $\mathrm{m}$ ranges between 1 and 8 [2-4]. Crystal structures of these oxides consist of $\mathrm{Bi}_{2} \mathrm{O}_{2}$ layers interleaved with m-perovskite layers of the composition $\mathrm{A}_{m-1} \mathrm{~B}_{m} \mathrm{O}_{3 m+1}$. When $m=1$ and $\mathrm{B}=\mathrm{V}^{5+}$, the formula can be written as $\mathrm{Bi}_{4} \mathrm{~V}_{2} \mathrm{O}_{11}$. The oxide $\mathrm{Bi}_{4} \mathrm{~V}_{2} \mathrm{O}_{11}$ with the Aurivillius layered perovskite structure was first reported by Venevtsev and later studied by Nowogrocki's group [5, 6].

Abraham et al. [6] characterized the parent compound $\left(\mathrm{Bi}_{4} \mathrm{~V}_{2} \mathrm{O}_{11}\right)$ by three essential polymorphs phase; $\alpha, \beta$ and $\gamma . \alpha$ (monoclinic and orthorhombic) phase exists at room temperature (RT) range and stable up to $440{ }^{\circ} \mathrm{C} ; \beta$ (orthorhombic) phase is stable in the temperature range $\left(440-560^{\circ} \mathrm{C}\right.$ ) and $\gamma$ (tetragonal) phase, which is fully oxygen disordered and found beyond $560{ }^{\circ} \mathrm{C}$. The highly pure $\alpha-\mathrm{Bi}_{4} \mathrm{~V}_{2} \mathrm{O}_{11}-\delta$ phase has monoclinic structure. If the compound contains low level of impurities in the starting material, it stabilizes to a closely related orthorhombic form. The $\gamma$-polymorph phase is a good oxide-ion conductor at moderate temperatures because of the fully disordered oxygen vacancies in the perovskite vanadate layers. Solid solutions with high oxide anion conductivity derived from parent compound $\mathrm{Bi}_{4} \mathrm{~V}_{2} \mathrm{O}_{11}$ by partial substitution for vanadium site possesses good oxide anion conductivity at intermediate temperature. These materials are used for various applications such as catalysts, gas sensors, solid-state electrolytes, fuel cells and oxygen pumps. Sei-Ki Kim et al. studied the Co doped at the B site of $\mathrm{Bi}_{4} \mathrm{~V}_{2}-{ }_{x} \mathrm{Co}_{x} \mathrm{O}_{11}-\delta$ and confirmed a high anisotropy of the ionic conductivity between the directions of both 
parallel and perpendicular to $\left(\mathrm{Bi}_{2} \mathrm{O}_{2}\right)^{2+}$ layer [7]. Gupta et al. studied the Barium doped $\mathrm{Bi}_{4} \mathrm{Ba}_{x} \mathrm{~V}_{2}-{ }_{x} \mathrm{O}_{11-\delta}$ $(0.0 \leq x \leq 0.15)$ using melt quench technique [8]. Ravi Kant et al. also studied the Ti doped $\mathrm{Bi}_{4} \mathrm{~V}_{2-x} \mathrm{Ti}_{x} \mathrm{O}_{11-\delta}$ $(0 \leq x \leq 0.4)$ [9]. Gupta et al. again studied $\mathrm{Bi}_{4} \mathrm{~V}_{2}-x$ $\mathrm{Mg}_{x} \mathrm{O}_{11-\delta}(x=0.05,0.10$ and 0.20$)$ and $\mathrm{Bi}_{4} \mathrm{~V}_{2}{ }_{x} \mathrm{Ca}_{x-}$ $\mathrm{O}_{11-\delta}(x=0.05,0.10,0.15$ and 0.20) [10]. Yasuda et al. studied the impedance analysis on electrical anisotropy of layer-structured $\mathrm{Bi}_{4} \mathrm{~V}_{2(1-\mathrm{x})} \mathrm{Co}_{2 x} \mathrm{O}_{11-\delta}$ single crystals [11]. Neelam Kumari et al. studied the dielectric, impedance and ferroelectric characteristics of C-oriented bismuth vanadate films grown by pulsed laser deposition [12]. Jugananda Sut et al. studied the A site doped lithium (Li) of $\mathrm{Bi}_{4-{ }_{x}} \mathrm{Li}_{x} \mathrm{~V}_{2} \mathrm{O}_{11-\delta}(0 \leq x \leq 0.4)$ [13]. Al-Areqi et al. studied the double substitution $(\mathrm{Co}, \mathrm{Ni})$ of A-site doped $\mathrm{BICO}_{0.20}-{ }_{x} \mathrm{NI}_{x} \mathrm{VO}_{x}(0 \leq x \leq 0.20)$ and found the maximum ionic conductivity at lower temperature $\left(\sim 2.56 \times 10^{-4} \mathrm{~S} \mathrm{Cm}^{-1}\right.$ at $\left.300{ }^{\circ} \mathrm{C}\right)$ for concentration $x=0.13$ [14]. Saba Beg et al. studied the structural and

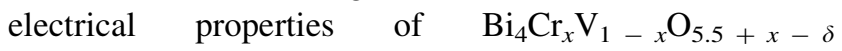
$(0 \leq x \leq 0.20)$ prepared by a micro wave-assisted route [15] and the effect of $\mathrm{Cu}-\mathrm{Al}$ double substitution on the electrical properties of $\mathrm{Bi}_{4} \mathrm{~V}_{2} \mathrm{O}_{11}$ [16]. Gupta et al. studied that the composition $\mathrm{Bi}_{4} \mathrm{~V}_{2}-{ }_{x} \mathrm{Sr}_{x} \mathrm{O}_{11-\delta}$ $(0.05 \leq x \leq 0.20)$ prepared by melt quench technique and found that the grain size increases with dopant concentration which leads to increase the dielectric constant [17]. The present paper reports the synthesis, structural, electrical (impedance and modulus) and conductivity properties of layered bismuth oxide structure compounds of Dy doped $\mathrm{Bi}_{4} \mathrm{~V}_{2}{ }_{x} \mathrm{Dy}_{x} \mathrm{O}_{11}(x=0.05,0.10,0.15$ and 0.20$)$ ceramics.

\section{Experimental}

\section{Materials preparation}

Solid-state reaction technique was used for the preparation of Dysprosium doped $\mathrm{Bi}_{4} \mathrm{~V}_{2}-{ }_{x} \mathrm{Dy}_{x} \mathrm{O}_{11}(x=0.05,0.10$, 0.15 and 0.20). High purity ingredients; $\mathrm{Bi}_{2} \mathrm{O}_{3}$ (99\%), $\mathrm{Dy}_{2} \mathrm{O}_{3}(99.9 \%), \mathrm{V}_{2} \mathrm{O}_{5}(98.5 \%)$ were taken in a suitable stoichiometry to synthesize all samples. The compositions were mixed thoroughly using mortar and pestle, first in an air atmosphere for $1 \mathrm{~h}$ and then in methanol for $2 \mathrm{~h}$ so as to prepare good homogeneous fine powder. Then the fine powders were calcined in a high purity alumina crucible at an optimized temperature of $700{ }^{\circ} \mathrm{C}$ for $3 \mathrm{~h}$ in an air atmosphere. The formation of the compounds were checked by X-ray diffraction technique (XRD) at room temperature. Then the fine homogenous calcined powder were cold pressed into cylindrical pellets of $12 \mathrm{~mm}$ diameter and 1-2 mm of thickness at a pressure of $4 \times 10^{6} \mathrm{~N} / \mathrm{m}^{2}$ using a hydraulic press. Polyvinyl alcohol
(PVA) was used as binder in the fine powder which was burnt out during the high temperature sintering. Then the pellets were sintered at $750{ }^{\circ} \mathrm{C}$ for $3 \mathrm{~h}$ in an air atmosphere. Finally, the sintered pellets were polished with fine emery paper to make both the surfaces smooth and parallel. The pellets were coated with high purity silver paste and dried at temperature $150{ }^{\circ} \mathrm{C}$ for $1 \mathrm{~h}$ to remove moisture, if any, and then cooled to room temperature before carrying out the measurements of electrical properties.

\section{Materials characterization}

X-ray diffraction analysis of the calcined homogenous fine powders were studied at room temperature using a diffractometer (ULTIMA IV Model-Rigaku, Japan) using $\mathrm{CuK} \alpha$ radiation $(\lambda=1.5405 \AA)$ in a wide range of Bragg's angle $2 \theta\left(20^{\circ} \leq \theta \leq 80^{\circ}\right)$ with a scanning speed of $3^{\circ} / \mathrm{min}$. The parameters such as electrical impedance $(Z)$, phase angle $(\theta)$, loss tangent $(\tan \delta)$ and capacitance $\left(C_{\mathrm{p}}\right)$ were measured using a computer-controlled impedance analyzer LCR meter (HIOKI Model: 3532) in laboratory-made sample holder and a heating arrangement in a wide frequency range $\left(10^{2}-10^{6} \mathrm{~Hz}\right)$ at different temperatures $\left(25-450{ }^{\circ} \mathrm{C}\right)$ of the samples.

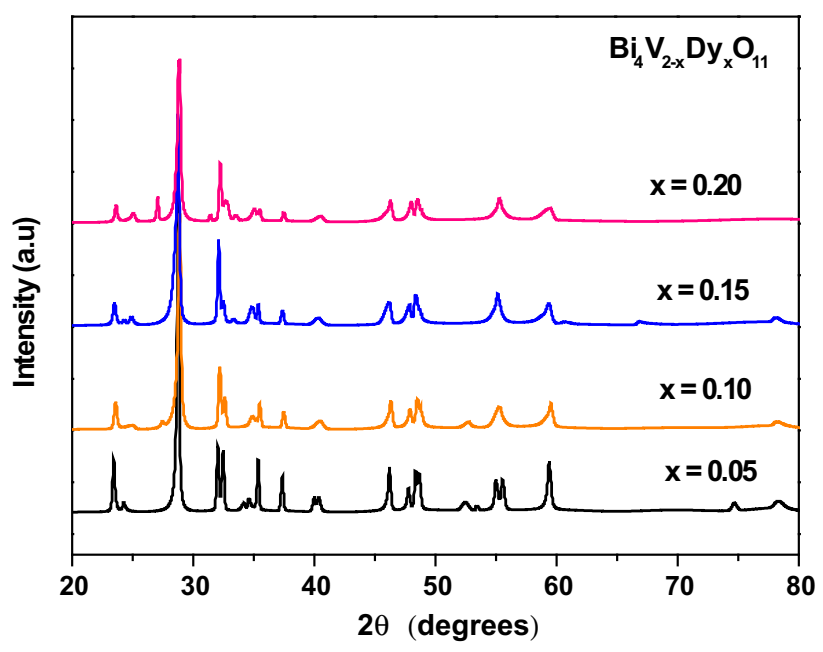

Fig. 1 XRD patterns of $\mathrm{Bi}_{4} \mathrm{~V}_{2}-{ }_{x} \mathrm{Dy}_{x} \mathrm{O}_{11}(x=0.05,0.10,0.15$ and 0.20 ) at room temperature

Table 1 Values of lattice parameters of $\mathrm{Bi}_{4} \mathrm{~V}_{2}-{ }_{x} \mathrm{Dy}_{x} \mathrm{O}_{11}(x=0.05$, $0.10,0.15$ and 0.20 )

\begin{tabular}{llllll}
\hline$x$ & $a(\AA)$ & $b(\AA)$ & $c(\AA)$ & $V\left(\AA^{3}\right)$ & Structure \\
\hline 0.05 & 5.563 & 5.609 & 15.382 & 479.96 & Orthorhombic \\
0.10 & 5.561 & 5.611 & 15.339 & 478.62 & Orthorhombic \\
0.15 & 5.560 & 5.618 & 15.335 & 479.01 & Orthorhombic \\
0.20 & 5.562 & 5.592 & 15.320 & 476.49 & Orthorhombic \\
\hline
\end{tabular}



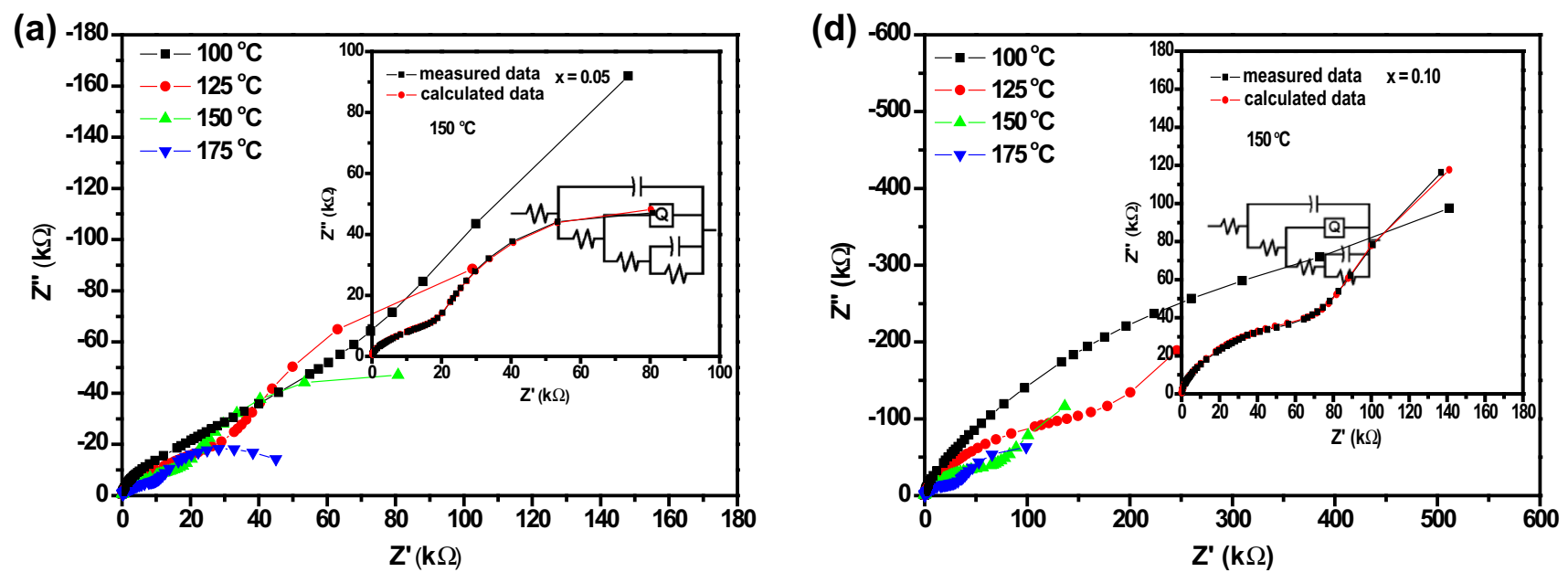

(b)

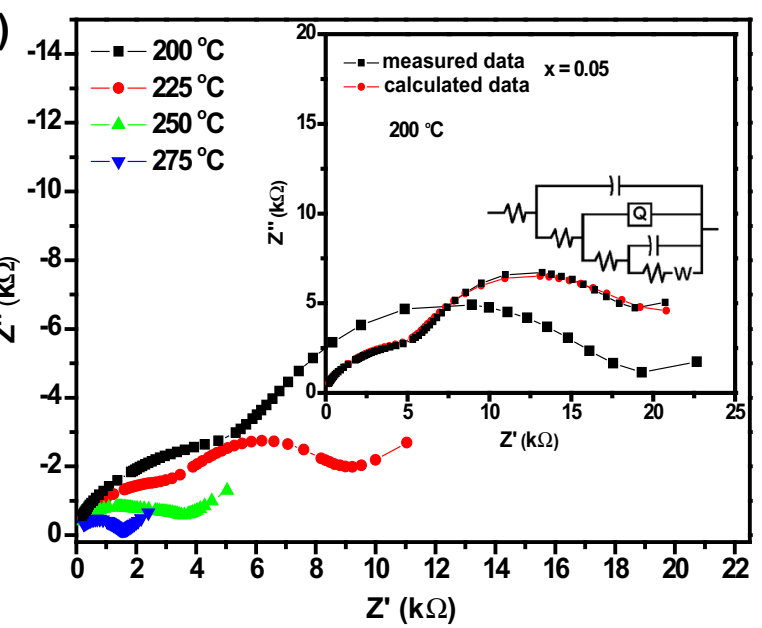

(e)

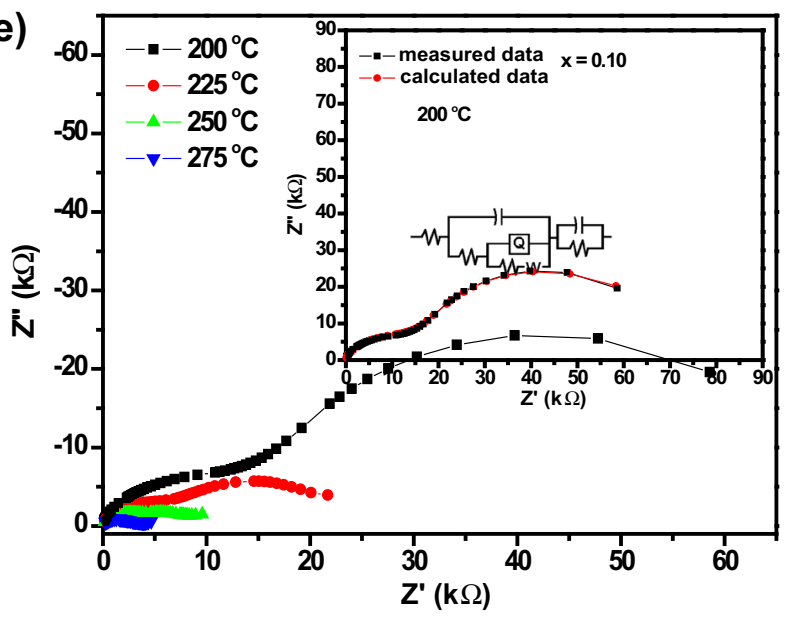

(c)
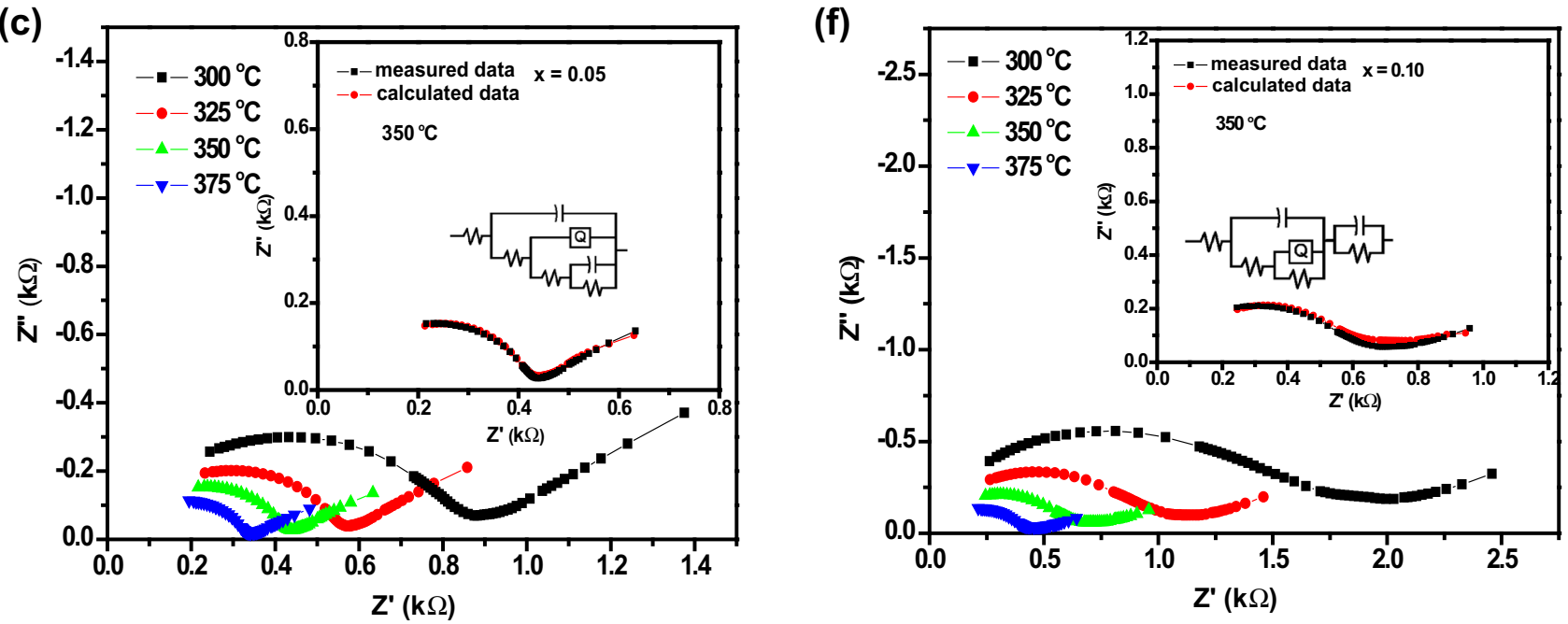

Fig. 2 a-f Complex impedance plot $\left(Z^{\prime}\right.$ vs. $\left.Z^{\prime \prime}\right)$ with equivalent circuit (inset) of $\mathrm{Bi}_{4} \mathrm{~V}_{2}-{ }_{x} \mathrm{Dy}_{x} \mathrm{O}_{11}(x=0.05$ and 0.10$)$ at different temperatures 

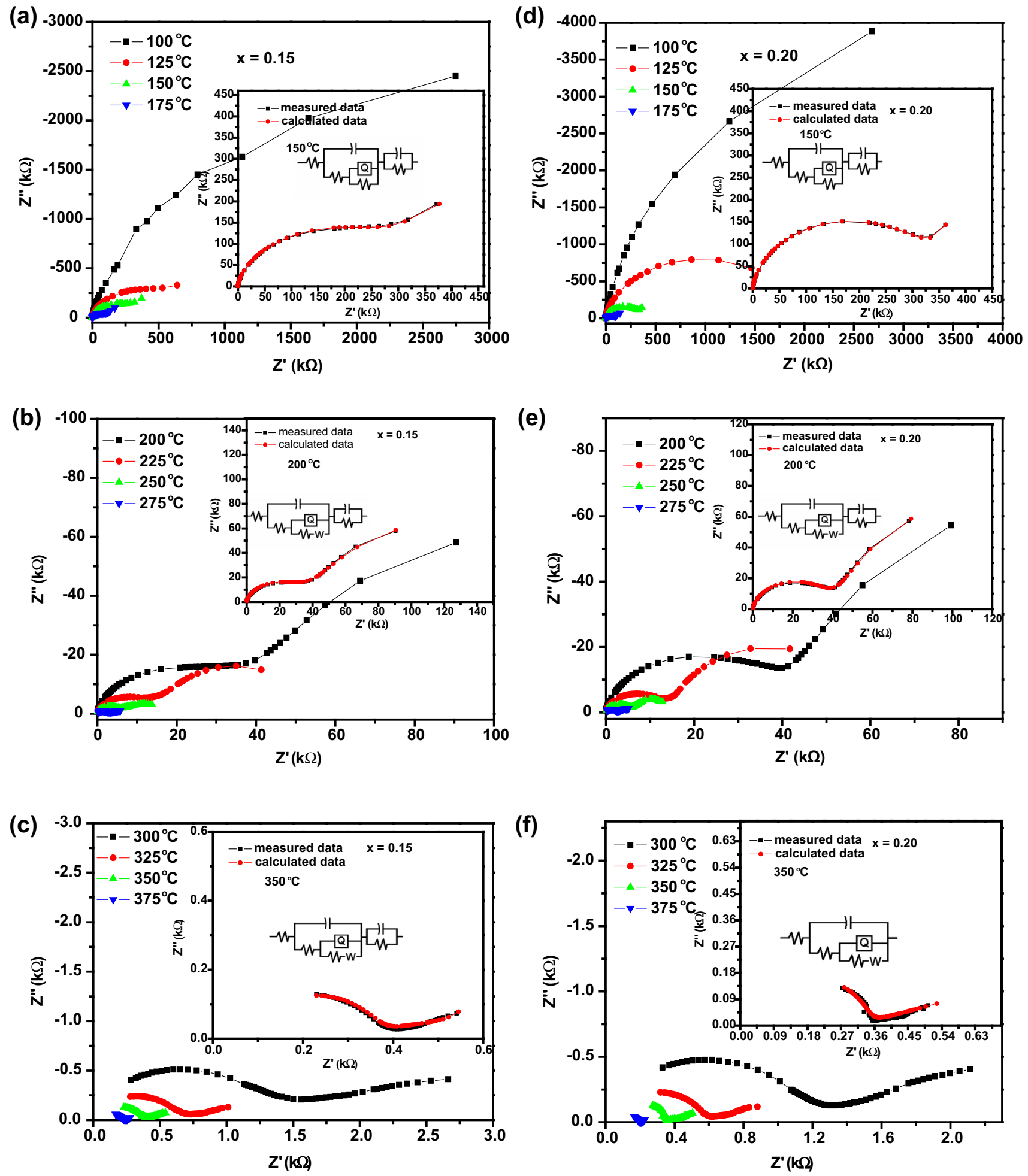

Fig. 3 a-f Complex impedance plot $\left(Z^{\prime}\right.$ vs. $\left.Z^{\prime \prime}\right)$ with equivalent circuit (inset) of $\mathrm{Bi}_{4} \mathrm{~V}_{2}-{ }_{x} \mathrm{Dy}_{x} \mathrm{O}_{11}(x=0.15$ and 0.20$)$ at different temperatures 
Table 2 Values of fitting parameters of the equivalent circuits of $\mathrm{Bi}_{4} \mathrm{~V}_{2}-{ }_{x} \mathrm{Dy}_{x} \mathrm{O}_{11}(x=0.05,0.10,0.15$ and 0.20$)$ at 150,200 and $350{ }^{\circ} \mathrm{C}$

\begin{tabular}{|c|c|c|c|c|c|}
\hline Temperatures & Fitting parameters & $x=0.05$ & $x=0.10$ & $x=0.15$ & $x=0.20$ \\
\hline \multirow[t]{9}{*}{$150^{\circ} \mathrm{C}$} & $\mathrm{R}_{1}$ & 52,700 & 42.66 & 409.9 & 2.384 \\
\hline & $\mathrm{R}_{2}$ & 4096 & $8.676 \times 10^{5}$ & 13,630 & 0.01 \\
\hline & $\mathrm{R}_{3}$ & 33,130 & $1.273 \times 10^{5}$ & $3.479 \times 10^{5}$ & $3.562 \times 10^{5}$ \\
\hline & $\mathrm{R}_{4}$ & $1.168 \times 10^{5}$ & $3.561 \times 10^{5}$ & $4.216 \times 10^{5}$ & $5.852 \times 10^{5}$ \\
\hline & $\mathrm{C}_{1}$ & $2.487 \times 10^{-10}$ & $2.235 \times 10^{-10}$ & $2.054 \times 10^{-10}$ & $1.694 \times 10^{-10}$ \\
\hline & $\mathrm{C}_{2}$ & $6.261 \times 10^{-9}$ & $7.154 \times 10^{-9}$ & $9.608 \times 10^{-9}$ & $1.412 \times 10^{-8}$ \\
\hline & $\operatorname{CPE}(Q)$ & $8.803 \times 10^{-8}$ & $5.611 \times 10^{-8}$ & $1.164 \times 10^{-8}$ & $1.993 \times 10^{-9}$ \\
\hline & Frequency power $(n)$ & 0.600 & 0.5544 & 0.8 & 0.7234 \\
\hline & Chi Square $\left(\chi^{2}\right)$ & $1.232 \times 10^{-4}$ & $2.203 \times 10^{-4}$ & $2.048 \times 10^{-4}$ & $1.418 \times 10^{-4}$ \\
\hline \multirow[t]{10}{*}{$200{ }^{\circ} \mathrm{C}$} & $R_{1}$ & 614.3 & 48.1 & 576.8 & 72.5 \\
\hline & $R_{2}$ & 1856 & 3632 & 10,210 & 13,410 \\
\hline & $R_{3}$ & 6711 & 15,940 & 25,920 & 24,390 \\
\hline & $R_{4}$ & 11,140 & 34,710 & 39,420 & 80,480 \\
\hline & $C_{1}$ & $2.655 \times 10^{-10}$ & $2.369 \times 10^{-10}$ & $2.159 \times 10^{-10}$ & $2.011 \times 10^{-10}$ \\
\hline & $C_{2}$ & $7.021 \times 10^{-9}$ & $1.466 \times 10^{-8}$ & $3.853 \times 10^{-8}$ & $3.557 \times 10^{-8}$ \\
\hline & $\operatorname{CPE}(Q)$ & $5.229 \times 10^{-8}$ & $8.128 \times 10^{-8}$ & $7.175 \times 10^{-9}$ & $1.882 \times 10^{-9}$ \\
\hline & Frequency power $(n)$ & 0.677 & 0.5856 & 0.8 & 0.8054 \\
\hline & Warburg $(W)$ & $1.032 \times 10^{-5}$ & $2.898 \times 10^{-6}$ & $7.326 \times 10^{-7}$ & $1.187 \times 10^{-6}$ \\
\hline & Chi Square $\left(\chi^{2}\right)$ & $2.194 \times 10^{-4}$ & $2.062 \times 10^{-4}$ & $2.998 \times 10^{-4}$ & $3.106 \times 10^{-4}$ \\
\hline \multirow[t]{10}{*}{$350{ }^{\circ} \mathrm{C}$} & $R_{1}$ & 96.82 & 105 & 98.61 & 0.01 \\
\hline & $R_{2}$ & 2815 & 302 & 0.001662 & 308.4 \\
\hline & $R_{3}$ & 681.2 & 686.3 & 61,640 & $1.000 \times 10^{15}$ \\
\hline & $R_{4}$ & $1.980 \times 10^{11}$ & 95.9 & $1.000 \times 10^{15}$ & \\
\hline & $C_{1}$ & $6.461 \times 10^{-10}$ & $4.958 \times 10^{-10}$ & $5.607 \times 10^{-10}$ & $2.045 \times 10^{-10}$ \\
\hline & $C_{2}$ & $2.724 \times 10^{-8}$ & $1.647 \times 10^{-5}$ & $9.507 \times 10^{-5}$ & \\
\hline & $\operatorname{CPE}(Q)$ & 0.0006123 & 0.0001058 & 0.001446 & 1.114 \\
\hline & Frequency power $(n)$ & 0.2688 & 0.2708 & 0.134 & 0.2108 \\
\hline & Warburg $(W)$ & & & $5.493 \times 10^{-8}$ & $1.000 \times 10^{-20}$ \\
\hline & Chi Square $\left(\chi^{2}\right)$ & $9.692 \times 10^{-5}$ & $7.131 \times 10^{-4}$ & $3.018 \times 10^{-4}$ & $1.279 \times 10^{-3}$ \\
\hline
\end{tabular}

\section{Results and discussion}

\section{Structural study}

At room temperature, compared XRD pattern shown in Fig. 1 of fine homogenous calcined powders for all Dy compositions of $\mathrm{Bi}_{4} \mathrm{~V}_{2}-{ }_{x} \mathrm{Dy}_{x} \mathrm{O}_{11}(x=0.05,0.10,0.15$ and 0.20$)$ were taken and confirmed an orthorhombic crystal structure. It is observed that, all the sample exhibit characteristic doublet at $2 \theta \approx 32^{\circ}$ and singlet at $2 \theta \approx 46^{\circ}$, which suggests the $\beta$ phase orthorhombic crystal structure at room temperature [16]. A good agreement between observed (obs) and calculated (cal) interplanar spacing $d\left(\sum \Delta d=d_{\mathrm{obs}}-d_{\mathrm{cal}}=\right.$ minimum $)$ was observed. The values of the lattice parameters shown in Table 1 were evaluated using a standard computer program package "POWD" [18] for all Dy concentration samples.
The crystallite size $(P)$ of Dy doped samples were roughly estimated from the broadening of a few XRD peaks (in a wide $2 \theta$ range) using the Scherrer's equation [19], $P=$ $K \lambda\left(\beta_{\frac{1}{2}} \cos \theta_{\mathrm{hkl}}\right)$ (where $K=$ constant $=0.89, \lambda=1.5405$ $\AA$ and $\beta_{1 / 2}=$ peak width of the reflection at half intensity). The average values of $P$ were found to be $21-40 \mathrm{~nm}$.

\section{Impedance study}

The complex impedance spectroscopy (CIS) [20] is the most important technique to study the electrical response (i.e., transport properties) of the material. Generally, the contribution of grain, grain boundary and electrode effect of a polycrystalline sample in a wide range of frequency at different temperatures can be analyzed. The electrical properties of the material is normally described in terms of complex dielectric constant $\left(\varepsilon^{*}\right)$, complex impedance $\left(Z^{*}\right)$, 

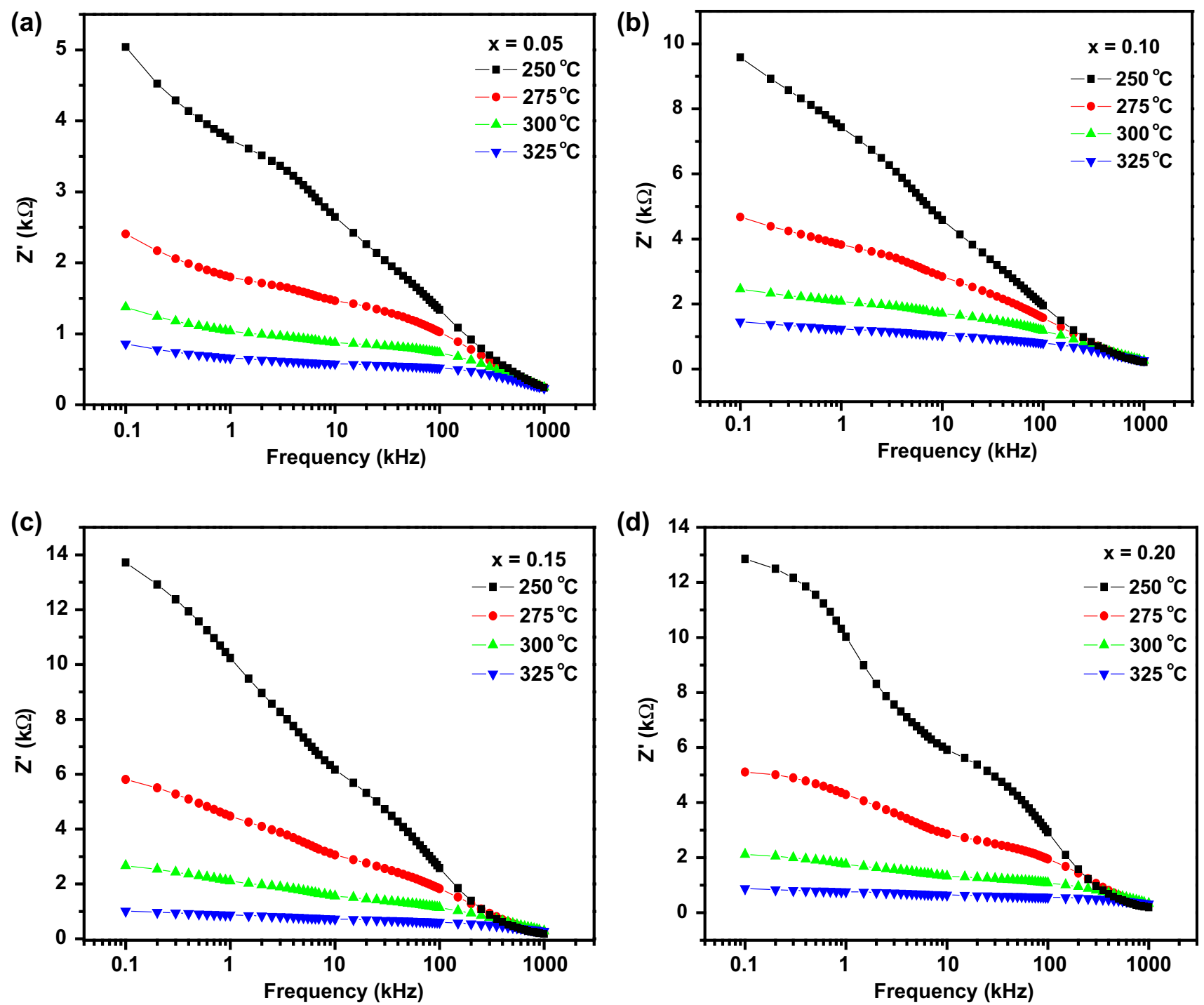

Fig. 4 a-d Variation of $Z^{\prime}$ with frequency of $\mathrm{Bi}_{4} \mathrm{~V}_{2}{ }_{-} \mathrm{Dy}_{x} \mathrm{O}_{11}(x=0.05,0.10,0.15$ and 0.20$)$ at different temperatures

electric modulus $\left(M^{*}\right)$ and loss tangent $(\tan \delta)$. These are related to each other as (1) $\varepsilon *=\varepsilon^{\prime}-j \varepsilon^{\prime \prime}(2) Z *=Z^{\prime}-j Z^{\prime \prime}$

(3) $M *=\frac{1}{\varepsilon *(\omega)}=M^{\prime}+j M^{\prime \prime}$ (4) $\tan \delta=\frac{\varepsilon^{\prime \prime}}{\varepsilon^{\prime}}=\frac{M^{\prime \prime}}{M^{\prime}}=\frac{Z^{\prime}}{Z^{\prime \prime}}$, where $\left(Z^{\prime}, M^{\prime}, \varepsilon^{\prime}\right)$ and $\left(Z^{\prime \prime}, M^{\prime \prime}, \varepsilon^{\prime \prime}\right)$ are real and imaginary components of impedance, modulus and permittivity. A complex impedance spectrum of ceramic sample shows two distinct features intragrain (grain) and intergrain (grain boundary). Impedance data are presented in the form of $Z^{\prime \prime}$ (capacitive) and $Z^{\prime}$ (resistive). The complex impedance of the electrode/ceramic/electrode configuration can be explained as the sum of a single $R C(R=$ resistance and $C=$ capacitance) circuit in parallel combination.

Figures $2 \mathrm{a}-\mathrm{f}$ and $3 \mathrm{a}-\mathrm{f}$ shows the complex impedance spectrum (called as Nyquist plot) i.e., $Z^{\prime}$ vs. $Z^{\prime \prime}$ of $\mathrm{Bi}_{4}$ $\mathrm{V}_{2}-{ }_{x} \mathrm{Dy}_{x} \mathrm{O}_{11}(x=0.05,0.10,0.15$ and 0.20$)$ over a wide range of frequency $(100 \mathrm{~Hz}-1 \mathrm{MHz})$ at different temperatures $\left(100-375^{\circ} \mathrm{C}\right)$. Generally, the semicircle at higher and lower frequencies represents grain and electrode effect, respectively, while at intermediate frequencies it represents the grain boundary contribution. In these cases, two semicircles are observed in the Nyquist plot; first semicircle at low frequency represents the resistance of the grain boundary and second at high frequency represents the resistance of grain properties. It shows from the Figs. $2 \mathrm{a}-\mathrm{f}$ and $3 \mathrm{a}-\mathrm{f}$ that a single semicircular arc appears for all the concentration up to $125^{\circ} \mathrm{C}$. Above $125^{\circ} \mathrm{C}$, two semicircular arcs are formed, which shows the contribution of both grain (at the higher frequency side) and grain boundaries (at the lower frequency side) effect with their centers lying below the real axis. This confirms the existence of nondebye type relaxation. Similar type of behavior is also observed in other Bi-layered structured compound [21]. The above property of the material arises due to the double parallel combination of resistance and capacitance. From 

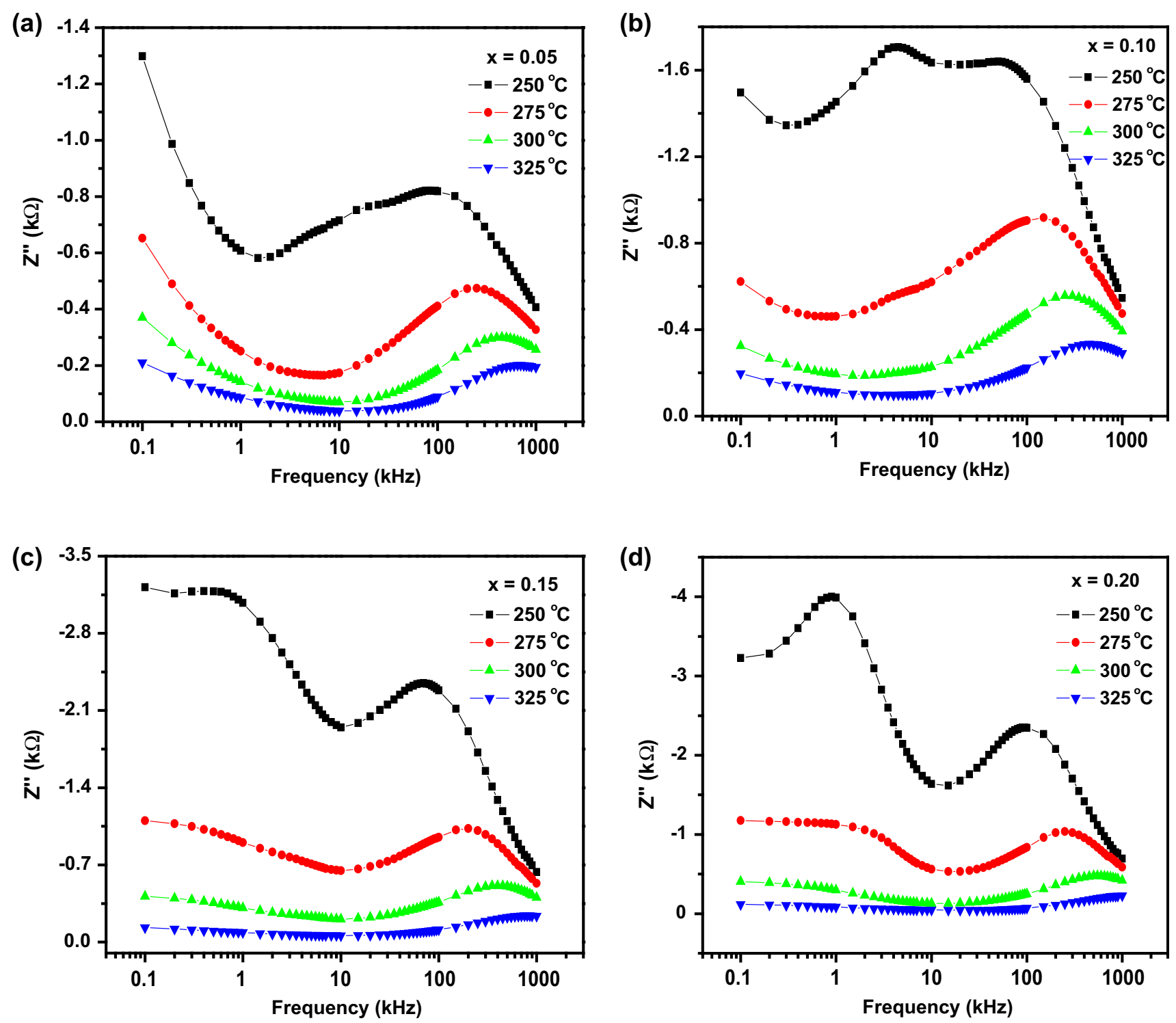

Fig. 5 a-d Variation of $Z^{\prime \prime}$ with frequency of $\mathrm{Bi}_{4} \mathrm{~V}_{2}-{ }_{x} \mathrm{Dy}_{x} \mathrm{O}_{11}(x=0.05,0.10,0.15$ and 0.20$)$ at different temperatures

the complex impedance spectrum, the intercept point on the real axis shifts towards the origin with the increase in temperature. It indicates the decrease in the resistive property, i.e., grain and grain boundary of the materials like a semiconductor. The impedance data are well fitted with the ZSimpWin software with an equivalent circuit as shown in the Fig. 2a-f (inset) and Fig. 3a-f (inset) at temperatures 150,200 and $350{ }^{\circ} \mathrm{C}$ for $x=0.05-0.20$, where $R, C, W$ and $Q$ are resistance, capacitance, warburg and constant phase element (CPE). The values of fitting parameters of the circuits are shown in Table 2.

Figure $4 a-d$ shows the variation of real part of the impedance $\left(Z^{\prime}\right)$ with frequency at different temperatures $\left(250-325{ }^{\circ} \mathrm{C}\right)$ of $\mathrm{Bi}_{4} \mathrm{~V}_{2}-{ }_{x} \mathrm{Dy}_{x} \mathrm{O}_{11}(x=0.05,0.10,0.15$ and 0.20$)$. It is observed that at lower frequency range, the magnitude of $Z^{\prime}$ (grain resistance) decreases with rise in temperature and appears to merge in the high frequency region. This may be due to the release of space charge polarization with rise in temperature and frequency [22]. On increasing the Dy concentration, the occurrence of space charge shifted to the higher frequency side. This may be due to the reduction in barrier properties of the materials with rise in temperature and responsible for the enhancement of conductivity. The space charge polarization occurs maximum at higher frequency side for $x=0.20$ as compared to the other Dy compositions. This may be possible due to the Dy doped on vanadium sites of the samples. It is also observed that the value of same resistance for $x=0.15$ and 0.20. Similar type of behavior is also observed in other studied material [17]. 

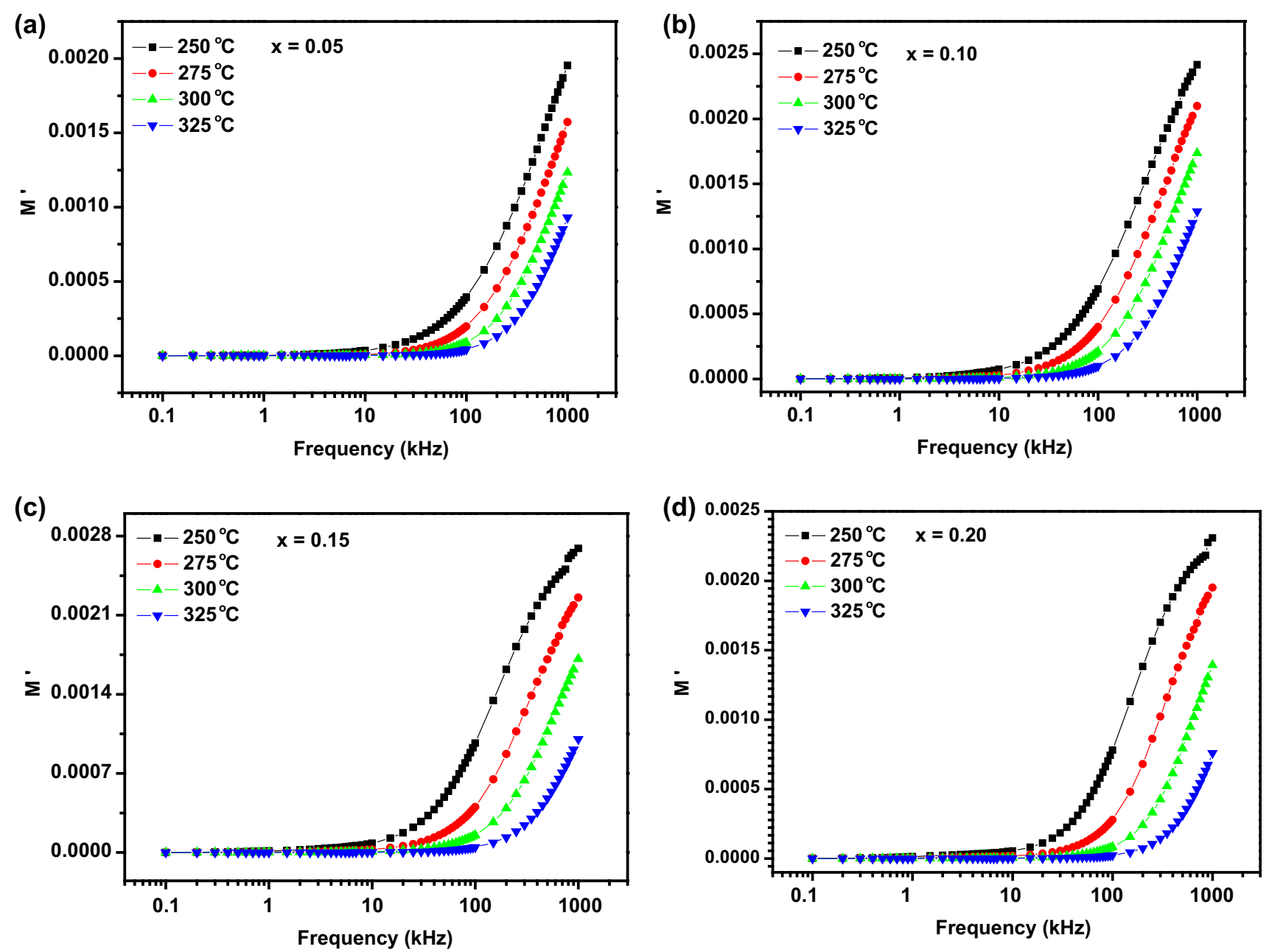

Fig. 6 a-d Variation of $M^{\prime}$ as a function of frequency of $\mathrm{Bi}_{4} \mathrm{~V}_{2}-{ }_{x} \mathrm{Dy}_{x} \mathrm{O}_{11}(x=0.05,0.10,0.15$ and 0.20$)$ at different temperatures

Figure 5a-d shows the variation of imaginary part of the impedance $\left(Z^{\prime \prime}\right)$, generally called as loss spectrum, with frequency at different temperatures $\left(250-325^{\circ} \mathrm{C}\right)$ of $\mathrm{Bi}_{4}$ $\mathrm{V}_{2}-{ }_{x} \mathrm{Dy}_{x} \mathrm{O}_{11} \quad(x=0.05,0.10,0.15$ and 0.20). From Fig. 5a, b, it is observed that, at low frequency region, $Z^{\prime \prime}$ initially decreases sharply with the increase in frequency and temperature but some peaks appear at intermediate frequency. These peaks are shifted towards higher frequency side in a decreasing manner, and finally, merge in the high frequency domain. From Fig. 5c, d, two peaks appeared in $Z^{\prime \prime}$ at low and intermediate frequency region. Again these two peaks are shifted towards higher frequency side. The $Z^{\prime \prime}$ peaks shifts to the lower frequencies with increasing Dy content, which indicates the presence of composition dependent electrical relaxation phenomenon in the system. This may by due to the immobile species at low temperatures and defect or vacancies at high temperatures [23]. The magnitude of $Z^{\prime \prime}$ decreases with increase in frequency, as well as with temperature for all the Dy concentration. At higher frequency, it is clear that there is an absence of space charge effect in the materials. Similar type of behavior is also observed in other studied material [16].

\section{Modulus study}

The complex modulus spectroscopy is a very convenient tool to study the dynamical aspects of electrical transport phenomena in the materials. Generally, the complex electrical impedance spectrum gives more emphasis to elements with large resistance, whereas complex electric modulus spectrum plots highlight those with smaller capacitance. Using the complex modulus formula, the inhomogeneous nature of the polycrystalline materials with grain and grain boundary effects can be probed easily, which cannot be distinguished from complex impedance plot. The other advantage of the electric modulus spectrum formulae is the suppressed electrode effect. The real and imaginary components of the complex electric modulus $\left(M^{*}\right)$ were calculated using the relation $M^{\prime}=\omega_{0} C_{0} Z^{\prime \prime}$, 

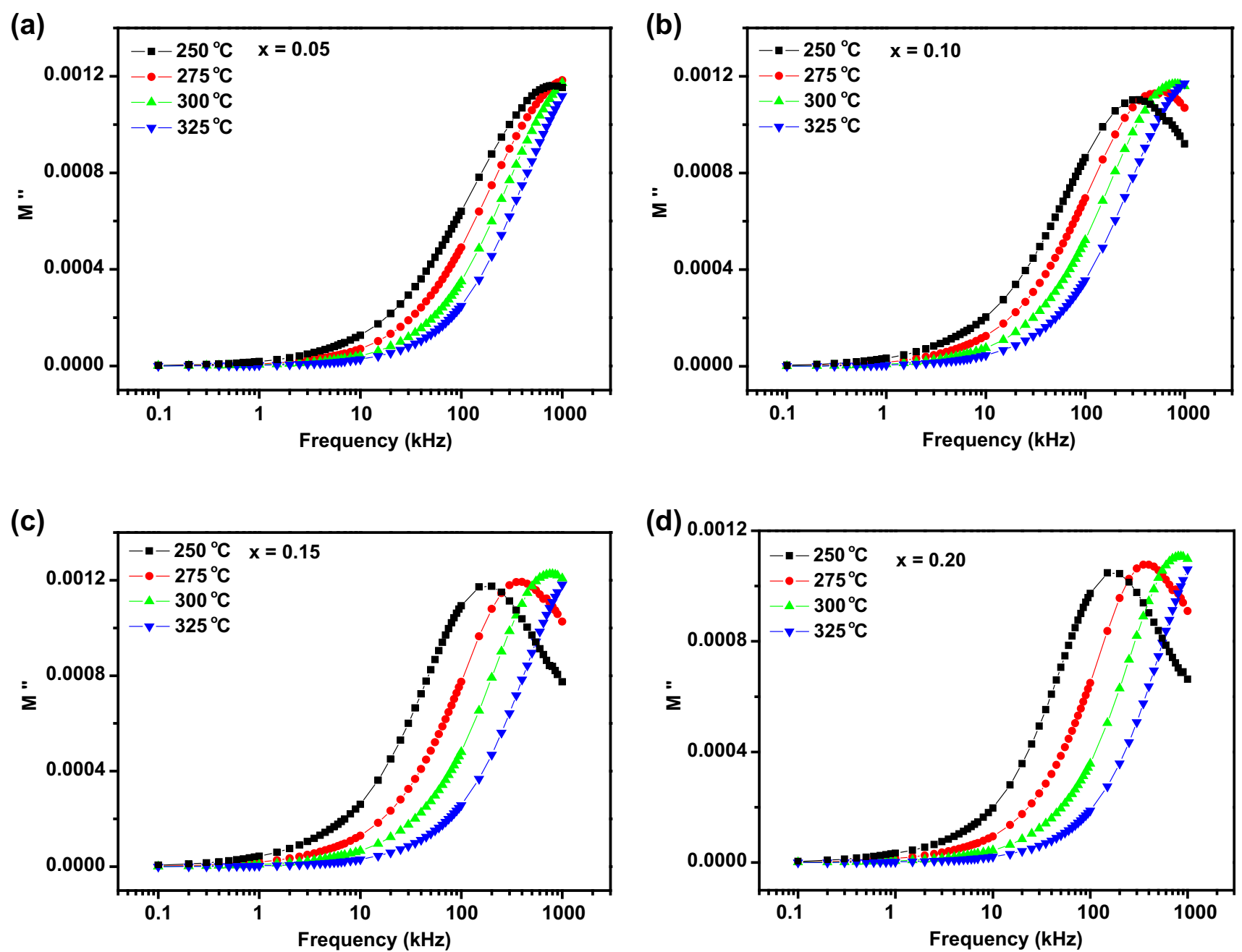

Fig. 7 a-d Variation of $M^{\prime \prime}$ as a function of frequency of $\mathrm{Bi}_{4} \mathrm{~V}_{2}-{ }_{x} \mathrm{Dy}_{x} \mathrm{O}_{11}(x=0.05,0.10,0.15$ and 0.20$)$ at different temperatures

$M^{\prime \prime}=\omega C_{0} Z^{\prime}\left(\omega=2 \pi f_{r}, C_{0}=\frac{\varepsilon_{0} A}{t}\right)$, where $\omega, C_{0}, \varepsilon_{0}, A, t$ and $f_{r}$ are the angular frequency, geometrical capacitance, permittivity of free space, area of the electrode surface, thickness and relaxation frequency.

Figure 6a-d shows the variation of $\mathrm{M}^{\prime}$ as a function of frequency of $\mathrm{Bi}_{4} \mathrm{~V}_{2}-{ }_{x} \mathrm{Dy}_{x} \mathrm{O}_{11}(x=0.05,0.10,0.15$ and $0.20)$ at different temperatures $\left(250-325{ }^{\circ} \mathrm{C}\right)$. For all the samples, at lower frequency region, it shows a very low value ( $\sim$ zero) of $M^{\prime}$. It shows a continuous increase in the dispersion with increase in frequency and then saturate at a maximum asymptotic value (i.e., $M_{\infty}$ ) in the higher frequency region. This may be due to the presence of conduction phenomenon, short range mobility of charge carriers and also may possibly be related to a lack of restoring force for flow of charges under the influence of steady electrical field. The value of $M^{\prime}$ decreases with rise in temperature in the high frequency region for all the Dy concentrations. Similar type of behavior also observed in other reported materials $[24,25]$.
Figure 7a-d shows the variation of imaginary part of electric modulus $\left(M^{\prime \prime}\right)$ with frequency of $\mathrm{Bi}_{4} \mathrm{~V}_{2}-{ }_{x} \mathrm{Dy}_{x} \mathrm{O}_{11}$ $(x=0.05,0.10,0.15$ and 0.20$)$ at different temperatures $\left(250-325^{\circ} \mathrm{C}\right)$. A well-defined relaxation mechanism are observed for the concentration $x=0.10-0.20$ at different temperatures expect $x=0.05$. The relaxation peaks shift towards higher frequency side with increase in temperature which correlates between the motions of mobile ions [26]. This suggests that the relaxation is thermally activated process. The asymmetry of peak broadening shows the spread of relaxation times with different time constant and hence the relaxation in the all compositions is of non-Debye type. The magnitude of the peak increases on increasing temperature. It is also observed that no peaks are obtained at $325{ }^{\circ} \mathrm{C}$ for all the Dy concentration of $x=0.05-0.20$.

Figure 8a-d shows the complex modulus spectrum $\left(M^{\prime}\right.$ vs. $\left.M^{\prime \prime}\right)$ of $\mathrm{Bi}_{4} \mathrm{~V}_{2}{ }_{x} \mathrm{Dy}_{x} \mathrm{O}_{11}(x=0.05,0.10,0.15$ and $0.20)$ at selected temperatures. The impedance data were again re-plotted in the modulus formula. A single 

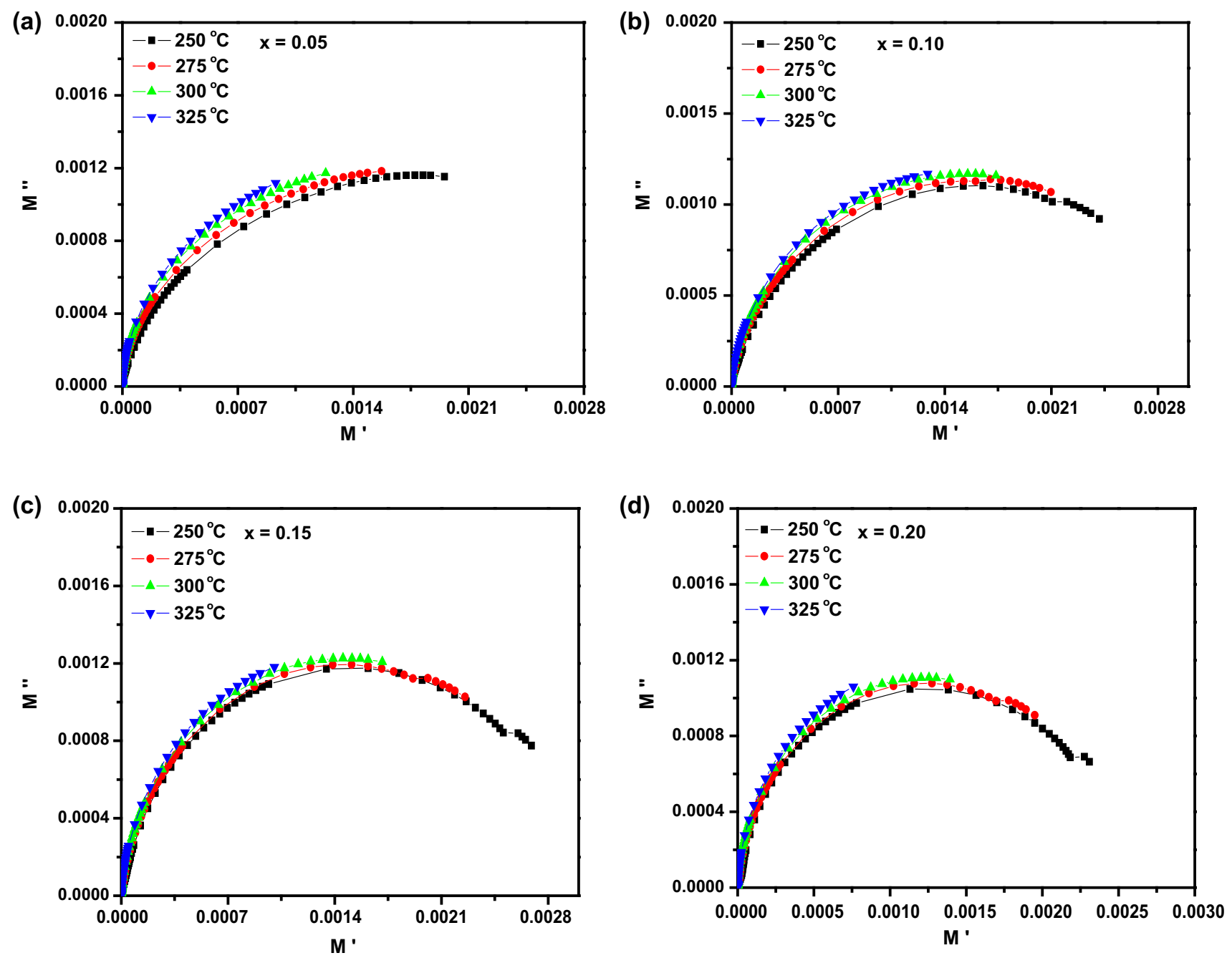

Fig. 8 a-d Complex modulus spectrum $\left(M^{\prime}\right.$ vs. $\left.M^{\prime \prime}\right)$ of $\mathrm{Bi}_{4} \mathrm{~V}_{2}-{ }_{x} \mathrm{Dy}_{x} \mathrm{O}_{11}(x=0.05,0.10,0.15$ and 0.20$)$ at different temperatures

semicircle is formed for all the Dy concentrations. It also confirms the presence of electrical relaxation phenomena in the materials. On increasing temperature, the intercept on real axis shifts towards the higher value of $M^{\prime}$. It indicates the increase in capacitance of the all Dy concentration of the materials. The intercept point on the real axis indicates that the grain effect contribute the total capacitance. It also supports the negative temperature co-efficient of resistance type behavior of the materials since the grain capacitance $\left(C_{\mathrm{g}}\right)$ is inversely proportional to the grain resistance $\left(R_{\mathrm{g}}\right)$. Similar type of results also observed in other reported material $[25,27]$.

\section{Electrical conductivity study}

Figure $9 \mathrm{a}-\mathrm{d}$ shows the ac electrical conductivity as a function of frequency of $\mathrm{Bi}_{4} \mathrm{~V}_{2}-{ }_{x} \mathrm{Dy}_{x} \mathrm{O}_{11}(x=0.05,0.10$, 0.15 and 0.20$)$ at different temperatures $\left(250-325{ }^{\circ} \mathrm{C}\right)$. It is observed that the value of $\sigma(\omega)$ increases with increase in frequency, as well as temperature for all Dy concentration. It can be also be explained as frequency dependent conductivity of the materials by Jonscher's universal power law [28] by the equation: $\sigma(\omega)=\sigma_{\mathrm{dc}}+A \omega^{n}$, where $\sigma_{d c}$ is a $\mathrm{dc}$ conductivity at frequency independent in particular range of temperature, ' $A$ ' is the temperature dependent parameter and ' $n$ ' is the power law exponent, $A \omega^{n}$ consisting of the ac dependence and characterizes for all dispersion phenomena. It is confirmed to be a typical fit of the parameters $A, n$ and $\sigma_{\mathrm{dc}}$ calculated by non-linear fit of the above equation with experimental data as shown in Table 3. The Navy blue solid lines are the fitted line for all the compositions. It is found that the value of the $\mathrm{n}$ vary between 0 and $1(0 \leq n \leq 1)$ depending on temperature. This suggests that the electrical conduction in the materials are also due to thermally activated process $[29,30]$. The ac conductivity is found to increase with increase in both frequency as well as Dy concentration. The conductivity pattern is a strongly dependent frequency and obeys a 

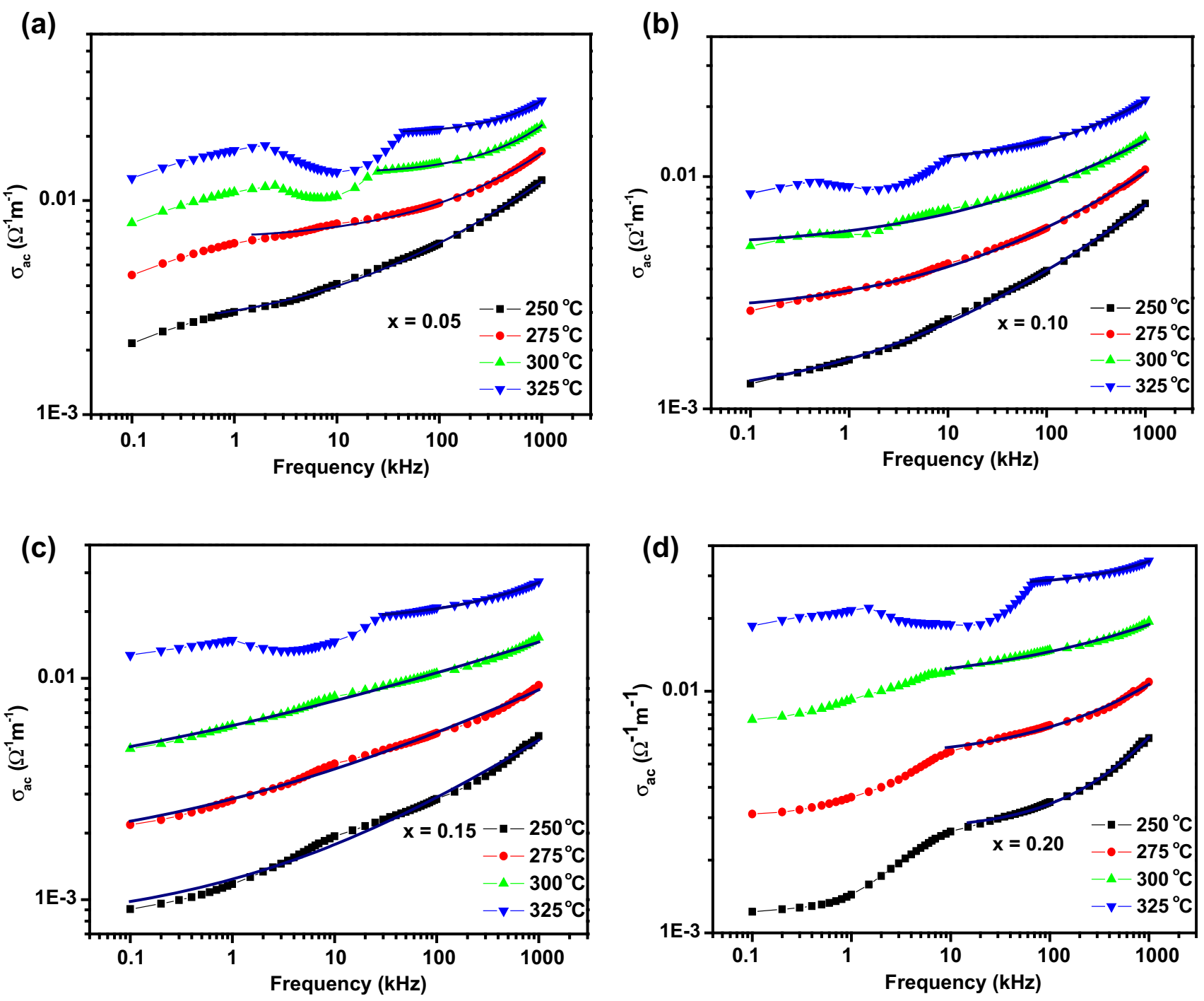

Fig. 9 a-d Variation of ac conductivity with frequency of $\mathrm{Bi}_{4} \mathrm{~V}_{2}{ }_{-} \mathrm{Dy}_{x} \mathrm{O}_{11}(x=0.05,0.10,0.15$ and 0.20$)$ at different temperatures

power relation $\sigma_{a c} \alpha \omega^{n}$ for all temperature. It clearly indicates that the low and high frequency dispersive regions are separated by a change in slope at a particular frequency at temperature $325^{\circ} \mathrm{C}$ for all concentration. There is an appearance of plateau region in the low frequency side and shows a change in slope at a particular frequency known as hopping frequency.

The electrical conductivity $\left(\sigma_{d c}\right)$ is thermally activated process and which obeys the Arrhenius law; $\sigma_{d c}=$ $\sigma_{0} \exp \left(\frac{-E_{a}}{K_{\mathrm{B}} T}\right)$, where the symbols having their usual meaning. Figure 10 shows the variation of $\sigma_{d c}$ (grain) with inverse of absolute temperature $\left(10^{3} / T\right)$ of $\mathrm{Bi}_{4} \mathrm{~V}_{2}-{ }_{x} \mathrm{Dy}_{x}$ $\mathrm{O}_{11}(x=0.05,0.10,0.15$ and 0.20$)$. The dc conductivity of the material were evaluated using the relation $\sigma=\frac{l}{R_{\mathrm{g}} A}$, where $l$ is the thickness, $R_{\mathrm{g}}$ is the grain resistance (calculated from Nyquist plot) and $A$ is the area of cross-section of the samples. A linear fit of $\sigma_{d c}$ vs. $\left(10^{3} / T\right)$ plot has been used to calculate from the slope of straight line. The values of activation energy $\left(E_{\mathrm{a}}\right)$ are found to be $0.40,0.49,0.73$ and $0.78 \mathrm{eV}$ for $x=0.05,0.10,0.15$ and 0.20 , respectively, in the temperature range $150-375^{\circ} \mathrm{C}$. The dc conductivity increases with increase in Dy concentration for all the samples. From the plot, it is clear that the grain resistance decreases with rise in temperature and indicates negative temperature co-efficient of resistance like a semiconductor.

\section{Conclusions}

The polycrystalline samples of $\mathrm{Bi}_{4} \mathrm{~V}_{2}-{ }_{x} \mathrm{Dy}_{x} \mathrm{O}_{11}$ ( $x=0.05-0.20)$ were prepared by the solid-state reaction technique has been studied. The phase formation is 
Table 3 Value of fitting parameters obtained from Jonscher's power law at different temperatures

\begin{tabular}{llllll}
\hline $\mathrm{x}$ & $T\left({ }^{\circ} \mathrm{C}\right)$ & $\sigma_{d c}\left(/ \Omega^{-1} \mathrm{~m}^{-1}\right)$ & $A$ & $n$ & Goodness of fit $\left(R^{2}\right)$ \\
\hline 0.05 & 250 & 0.00246 & $3.71171 \times 10^{-5}$ & 0.40363 & 0.99917 \\
& 275 & 0.00655 & $9.63276 \times 10^{-6}$ & 0.50371 & 0.99682 \\
& 300 & 0.01337 & $1.32853 \times 10^{-7}$ & 0.80596 & 0.99952 \\
0.10 & 325 & 0.02065 & $1.37928 \times 10^{-8}$ & 0.96657 & 0.99969 \\
& 250 & 0.00107 & $5.06305 \times 10^{-5}$ & 0.35088 & 0.99929 \\
& 275 & 0.00256 & $5.64477 \times 10^{-5}$ & 0.35777 & 0.99869 \\
& 300 & 0.0049 & $9.50668 \times 10^{-5}$ & 0.33246 & 0.99485 \\
0.15 & 325 & 0.0114 & $6.75685 \times 10^{-6}$ & 0.52696 & 0.99761 \\
& 250 & 0.00074 & $5.29324 \times 10^{-5}$ & 0.32173 & 0.99381 \\
& 275 & 0.00148 & $2.55965 \times 10^{-4}$ & 0.24351 & 0.99501 \\
& 300 & 0.00248 & 0.00109 & 0.17416 & 0.99427 \\
0.20 & 325 & 0.018 & $5.26265 \times 10^{-6}$ & 0.53953 & 0.99729 \\
& 250 & 0.00266 & $2.38173 \times 10^{-7}$ & 0.70042 & 0.9974 \\
& 275 & 0.00522 & $9.32949 \times 10^{-6}$ & 0.46114 & 0.99244 \\
& 300 & 0.01045 & $1.13238 \times 10^{-4}$ & 0.31206 & 0.98908 \\
& 325 & 0.02743 & $3.57317 \times 10^{-7}$ & 0.71605 & 0.98891 \\
\hline
\end{tabular}

Fig. 10 Variation of dc conductivity with inverse of temperature of $\mathrm{Bi}_{4} \mathrm{~V}_{2}-{ }_{x} \mathrm{Dy}_{x} \mathrm{O}_{11}(x=0.05$, $0.10,0.15$ and 0.20 )

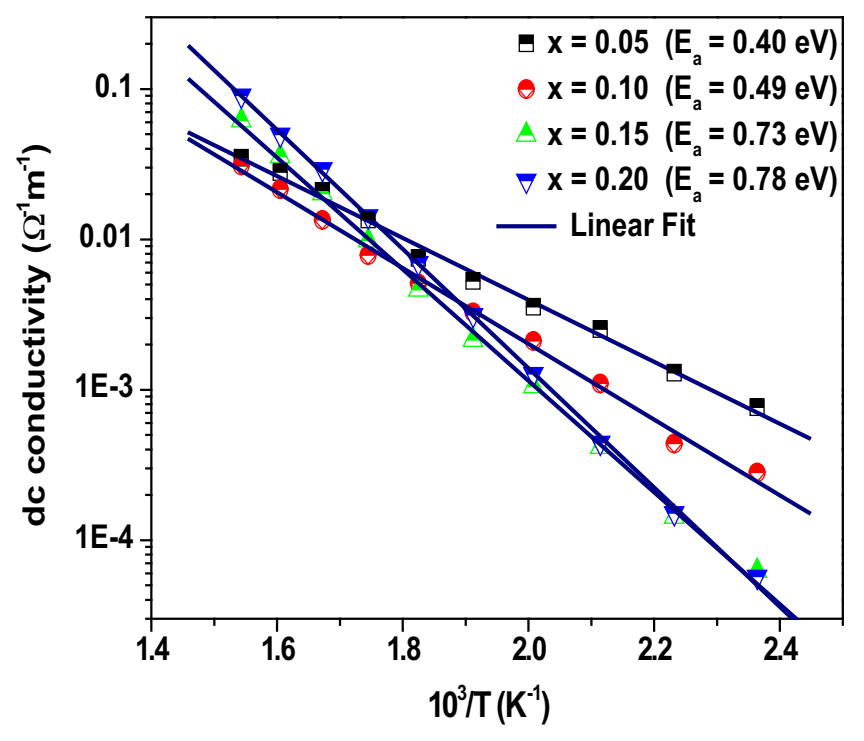

Acknowledgments One of the authors (SB) acknowledges the financial support through RGNF of UGC to carry out the research work. The authors also acknowledge the financial support through DRS-I of UGC, New Delhi, India under SAP and FIST programme of DST, New Delhi, India for the development of research work in the School of Physics, Sambalpur University, Odisha. One of the authors (BB) acknowledge to the SERB under DST Fast Track Scheme for young Scientist (Project No. SR/FTP/PS-036/2011) New Delhi, India.

Open Access This article is distributed under the terms of the Creative Commons Attribution 4.0 International License (http://creative commons.org/licenses/by/4.0/), which permits unrestricted use, distribution, and reproduction in any medium, provided you give appropriate credit to the original author(s) and the source, provide a link to the Creative Commons license, and indicate if changes were made. 


\section{References}

1. Aurivillius, B.: Mixed bismuth oxides with layer lattice I. Traducido de. Arkiv. Kemi. 1, 463-480 (1949)

2. Wolfe, R.W., Newnham, R.E., Kay, M.I.: Crystal structure of $\mathrm{Bi}_{2} \mathrm{WO}_{6}$. Solid State Commun. 7, 1797-1801 (1969)

3. Subbarao, E.C.: Crystal chemistry of mixed bismuth oxide with layer-type structure. J. Am. Ceram. Soc. 45, 166-169 (1962)

4. Ismailzade, I.G., Nesterenko, V.I., Mirishli, F.A., Rustamov, P.G.: X-ray and electrical studies of the system $\mathrm{Bi}_{4} \mathrm{Ti}_{3} \mathrm{O}_{12^{-}}$ $\mathrm{BiFeO}_{3}$. Soviet Phys. Crys. 12, 400-404 (1967)

5. Bush, A.A., Koshelayeva, V.G., Venevtsev, Y.N.: Crystals of the $\mathrm{Bi}_{2} \mathrm{GeO}_{5}-\mathrm{Bi}_{4} \mathrm{~V}_{2} \mathrm{O}_{11}$ system. J. Appl. Phys. 24, 625-627 (1985)

6. Abraham, F., Debreuille-Gresse, M.F., Mairesse, G., Nowogrocki, G.: Phase transitions and ionic conductivity in $\mathrm{Bi}_{4} \mathrm{~V}_{2} \mathrm{O}_{11}$ an oxide with a layered structure. Solid State Ionics 28-30, 529-532 (1988)

7. Kim, S.K., Miyayama, M.: Anisotropy in oxide-ion conductivity of $\mathrm{Bi}_{4} \mathrm{~V}_{2-\mathrm{x}} \mathrm{Co}_{\mathrm{x}} \mathrm{O}_{11-\delta}$. Solid State Ionics 104, 295-302 (1997)

8. Gupta, S., Singh, K.: Structural and optical properties of melt quenched barium doped bismuth vanadate. Phys. B 431, 89-93 (2013)

9. Kant, R., Singh, K., Pandey, O.P.: Structural and ionic conductive properties of $\mathrm{Bi}_{4} \mathrm{~V}_{2-\mathrm{x}} \mathrm{Ti}_{\mathrm{x}} \mathrm{O}_{11-\delta}(0 \leq \mathrm{x} \leq 0.4)$ compound. Mater. Sci. Eng. B 158, 63-68 (2009)

10. Gupta, S., Singh, K.: Effect of two different dopants $\left(\mathrm{Mg}^{2+}\right.$ and $\mathrm{Ca}^{2+}$ ) and processing parameters on $\gamma$-phase stabilization and conductivity of $\mathrm{Bi}_{4} \mathrm{~V}_{2} \mathrm{O}_{11-\delta}$. Ceram. Int. 41, 9496-9504 (2015)

11. Yasuda, N., Miyayama, M., Kudo, T.: Impedance analysis on electrical anisotropy of layer-structured $\mathrm{Bi}_{4} \mathrm{~V}_{2}(1-\mathrm{x}) \mathrm{Co}_{2 \mathrm{x}} \mathrm{O}_{11-\delta}$ single crystals. Mater. Res. Bull. 36, 323-333 (2001)

12. Kumari, N., Krupanidhi, S.B., Varma, K.B.R.: Dielectric, impedance and ferroelectric characteristics of C-oriented bismuth vanadate films grown by pulsed laser deposition. Mater. Sci. Eng. B. 138, 22-30 (2007)

13. Sut, J., Borah, L., Pandey, A.: Synthesis, structure and electrical conductivity of Li-substituted $\mathrm{Bi}_{4} \mathrm{~V}_{2} \mathrm{O}_{11}$ solid electrolyte. Int. J. Innov. Res. Develop. 1, 181-185 (2012)

14. Al-Areqi Niyazi, A.S., Beg, S., Al-Alas, A., Hafeez, S.: Study on phase stabilization performance of $\mathrm{BiCo}_{0.20-\mathrm{x}} \mathrm{Ni}_{\mathrm{x}} \mathrm{VO}_{\mathrm{x}}$ solid electrolyte. Phase Transition 87, 96-109 (2014)

15. Beg, S., Al-Alas, A., Al-Areqi Niyazi, A.S.: Structural and electrical properties of hexavalent-substituted BIMEVOX synthesized by a microwave-assisted route. Radiat. Effect Defects Solid Inc. Plasma Sci. Plasma Technol. 165, 894-906 (2010)
16. Beg, S., Salami, N.S.: Effect of $\mathrm{Cu}-\mathrm{Al}$ double substitution on the electrical properties of $\mathrm{Bi}_{4} \mathrm{~V}_{2} \mathrm{O}_{11}$. Phase Transitions 88, 59-73 (2015)

17. Gupta, S., Singh, K.: Dielectric, optical and structural properties of $\mathrm{Bi}_{4} \mathrm{~V}_{2-\mathrm{x}} \mathrm{Sr}_{\mathrm{x}} \mathrm{O}_{11-\delta}(0.05 \leq \mathrm{x} \leq 0.20)$. J. Phys. Chem. Solids 85, $18-25$ (2015)

18. Wu, E., POWD.: An Interactive Powder Diffraction Data Interpretation and Indexing Program. Ver 2.1, School Physical Science. Flinders University, South Bedford Park

19. Scherrer, P.: Gottinger Nachrichten. Math. Phys. 2, 98-100 (1918)

20. Macdonald, J.R.: Impedance Spectroscopy. John Wiley and Sons, New York (1987)

21. Beg, S., Al- Areqi, N.A.S., Haneef, S.: Study of phase transition and ionic conductivity changes of Cd-substituted $\mathrm{Bi}_{4} \mathrm{~V}_{2} \mathrm{O}_{11-\delta}$. Solid State Ionics 179, 2260-2264 (2008)

22. Behera, B., Nayak, P., Choudhary, R.N.P.: Structural, dielectric and impedance properties of $\mathrm{NaCa}_{2} \mathrm{~V}_{5} \mathrm{O}_{15}$ ceramics. Curr. Appl. Phys. 9, 201-205 (2009)

23. Singh, H., Kumar, A., Yadav, K.L.: Structural, dielectric, magnetic, magnetodielectric and impedance spectroscopic studies of multiferroic $\mathrm{BiFeO}_{3}-\mathrm{BaTiO}_{3}$ ceramics. Mater. Sci. Eng. 176, 540-547 (2011)

24. Behera, B., Nayak, P., Choudhary, R.N.P.: Studies of dielectric and impedance properties of $\mathrm{KCa}_{2} \mathrm{~V}_{5} \mathrm{O}_{15}$ ceramics. J. Phys. Chem. Solids 69, 1990-1995 (2008)

25. Behera, B., Nayak, P., Choudhary, R.N.P.: Study of complex impedance spectroscopic properties of $\mathrm{LiBa}_{2} \mathrm{Nb}_{5} \mathrm{O}_{15}$ ceramics. Mater. Chem. Phys. 106, 193-197 (2007)

26. Borsa, F., Torgeson, D.R., Martin, S.W., Patel, H.K.: Relaxation and fluctuations in glassy fast-ion conductors: wide-frequencyrange NMR and conductivity measurement. Phys. Rev. B. 46, 795-800 (1992)

27. Das, P.R., Pati, B., Sutar, B.C., Choudhary, R.N.P.: Electrical properties of complex tungsten bronze ferroelectrics; $\mathrm{Na}_{2} \mathrm{~Pb}_{2} \mathrm{R}_{2}$ $\mathrm{W}_{2} \mathrm{Ti}_{4} \mathrm{Nb}_{4} \mathrm{O}_{30}(\mathrm{R}=\mathrm{Gd}, \mathrm{Eu})$. Adv. Mat. Lett. 3, 8-14 (2012)

28. Jonscher, A.K.: The 'universal' dielectric response. Nature $\mathbf{2 6 7}$ 673-679 (1977)

29. Mohanty, N.K., Pradhan, R.N., Satpathy, S.K., Behera, A.K., Behera, B., Nayak, P.: Electrical transport properties of layered structure bismuth oxide: $\mathrm{Ba}_{0.5} \mathrm{Sr}_{0.5} \mathrm{Bi}_{2} \mathrm{~V}_{2} \mathrm{O}_{9}$. J. Mater. Sci. Mater. Electron. 25, 117-123 (2014)

30. Khatri, P., Behera, B., Srinivas, V., Choudhary, R.N.P.: Structural and dielectric properties of $\mathrm{Ba}_{3} \mathrm{~V}_{2} \mathrm{O}_{8}$ ceramics. Curr. Appl. Phys. 9, 515-519 (2009) 